\title{
Friction Forces and Mechanical Dust Generation in an Iron Ore Pellet Bed Subjected to Varied Applied Loads
}

\author{
Muhammad NABEEL, ${ }^{*}$ Andrey KARASEV and Pär Göran JÖNSSON \\ KTH Royal Institute of Technology, Brinellvägen 23, MSE, SE-10044 Stockholm, Sweden. \\ (Received on September 1, 2016; accepted on December 6, 2016; J-STAGE Advance published date: \\ March 7, 2017)
}

\begin{abstract}
Iron ore pellets degrade and generate dust during transportation and handling as well as during the iron making process. This leads to material losses and effects the process efficiency in a negative manner. In order, to reduce the generation of dust it is important to understand the influence of process parameters on the dust formation. An experimental setup was used to measure the dust generation and friction forces caused by abrasion of iron ore pellets in a closed pack bed. A varied load of 1 to $3 \mathrm{~kg}$ was applied on the pellet bed but at a constant air flow rate to capture the airborne dust particles. It was observed that an increase of $\sim 67 \%$ is observed in the friction and the dust generation in the bed as the applied load increased from 1 to $3 \mathrm{~kg}$. Moreover, the evaluation of the particle size distribution of the generated dust showed that a higher friction in the pellet bed can lead to an increased amount of airborne particles. Moreover, it has been shown that in an air flow the morphology and the orientation of dust particles can influence the air velocity required to transport the particles upwards.
\end{abstract}

KEY WORDS: friction; dust generation; iron ore pellets; ironmaking; mechanical wear.

\section{Introduction}

Over the past couple of decades, the blast furnaces (BF) in the Nordic region has shifted from using a mixture of iron ore sinter and pellets to using $100 \%$ pellets as raw materials. This transition is beneficial due to the advantages of pellets in comparison to sinter such as a more regular particle size distribution, a consistency in the chemical composition and a good reducibility. ${ }^{1)}$ Moreover, better operating results can be achieved in term of productivity and fuel rate by using $100 \%$ pellets in comparison to sinter. ${ }^{2)}$ However, it has been reported that $\mathrm{BF}$ operations using $100 \%$ pellets generate higher amounts of flue dust (mainly Fe oxide and C particles) compared to operations with a mixture of sinter and pellets. ${ }^{3)}$ Based upon an investigation of off-gas dust, it has been concluded that the Fe oxide particles in flue dust are mechanically formed due to abrasion of the pellets. ${ }^{4)}$ Moreover, a considerable amount of dust is generated due to the mechanical wear/degradation of iron ore pellets during transportation and handling. This amount depends on the severity of the transportation and handling steps such as the vessel loading systems, the number and height of drops, the length of conveyor belts and the descending velocities in side bins.

The generation of dust either during transportation and handling or during ironmaking process is undesired, since it leads to materials loss and causes environmental problems as it becomes airborne during transportation and in the

\footnotetext{
* Corresponding author: E-mail: mnabeel@kth.se

DOI: http://dx.doi.org/10.2355/isijinternational.ISIJINT-2016-514
}

production facility. Moreover, in the BF operation the dust particles clog the voids present in the burden, which have an influence on the flow of reducing gases. This results in an increased coke consumption and a reduced efficiency of the operation. ${ }^{5,6)}$

Copeland and Kawatra $^{7}$ have developed a dust tower to investigate the airborne particulate generation from iron ore pellets. This dust tower has been used to investigate the effect of different factors on the dust generation tendency of pellets, such as the pellet chemistry, firing temperature, coke breeze addition, abrasion index and compressive strength. ${ }^{8-10)}$ It was reported that the pellet chemistry and pellet firing temperature are the main factors influencing the dust generation. ${ }^{8}$ These investigations provide an insight about the relationship between the pelletization and dust generation. However, the factors which might influence the dust generation during transport and handling were not considered.

In previous studies iron ore lumps and pellets have been subjected to drop tests, vibration tests and standard tumble drum tests to investigate the influence of the particulate size and number and height of drops on the degradation.,11,12) For iron ore pellets, the fraction of material under $0.5 \mathrm{~mm}$ is usually reported as dust. However, in the case of the BF process operating with $100 \%$ iron ore pellet, the dominant fraction of particles in the flue dust is $<0.063 \mathrm{~mm}$. ${ }^{4)}$ There exists insufficient data regarding the influence of handling parameters on the generation of particles which can be airborne and which can be found in BF flue gases.

Apart from this, information regarding friction between pellets can be of great use for researchers working with 
simulation and modeling of the burden descend in a BF. Gustafsson et al. ${ }^{13)}$ has reported an average friction coefficient of 0.67 and 0.72 for a sliding contact between pellet to pellet and pellet to steel plate, respectively. However, there is need to have information regarding the friction in a pellet bed as well as on the influence of different process parameters on the friction.

The objective of this study was to investigate the friction forces and the dust generation in a pellet bed under conditions of different applied loads on the bed. In addition, the particle size distributions of dust generated during different experimental conditions have been investigated and compared. Based upon obtained results, the mechanisms of mechanical wear of pellets and dust generation are discussed.

\section{Experimental Method}

\subsection{Wear Experiments}

An equipment was designed to simulate the mechanical wear of pellets and to measure the friction force in a closed pack bed of pellets. Figure 1 presents a schematic illustration of the equipment. The pellets lie in the container on the bottom plate which rotates by a motor. While the pellets are rotating along with the bottom plate, they exert frictional forces on the walls of cylinder and upper loading plate. This makes the upper loading plate and loading rod to rotate along with the pellets. The friction force, which is experienced amongst the pellet bed, is transferred through the loading rod and measured by the load cell. A S2M force load cell with a measuring range from $0-20 \mathrm{~N}$ was used for the friction measurements. The signals from the force load cell were acquired at a frequency of $2 \mathrm{~Hz}$. For decreasing of additional generation of dust due to the friction between pellets and bottom/upper metal plates, the inside surfaces of metal plates were covered by a soft natural rubber. The equipment also consists of an inlet and outlet for air flow. The outlet was connected to a particle counter to continuously measure the particle size distribution (PSD) of dust

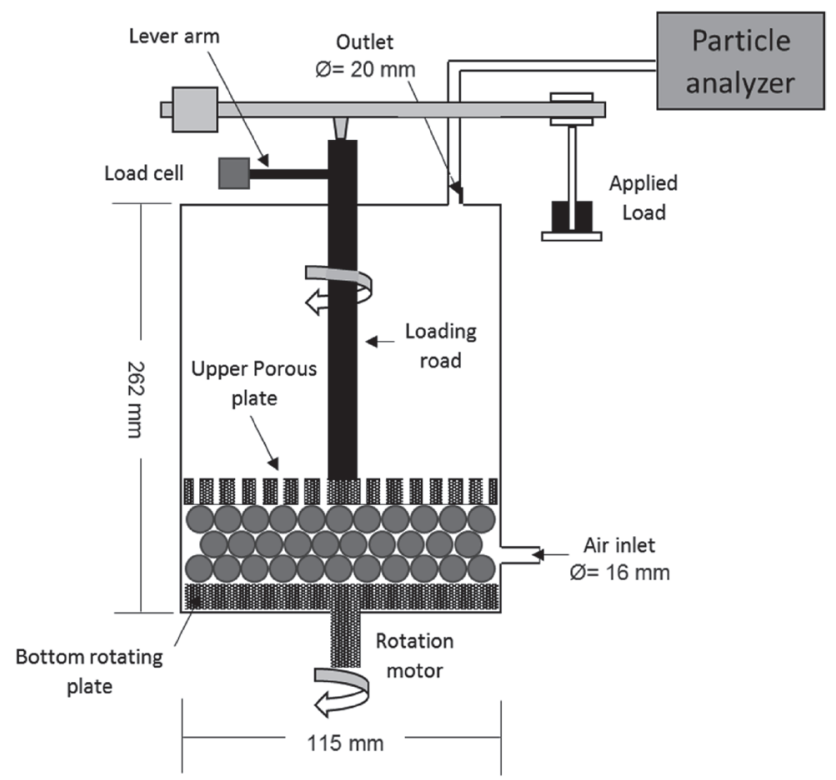

Fig. 1. Schematic illustration of the test equipment. particles in the air flow. In addition, the dust particles which did not exit the container with the air flow were collected at the bottom of container.

Commercial pellets (MPBO) provided by LKAB (Sweden) were used for the investigations. In a previous study, ${ }^{14)}$ the MPBO pellets were classified into three groups according their weight $(W)$ and size $\left(D_{\text {eq }}\right)$ : Group A - small sized pellets $\left(W<3.0 \mathrm{~g}, D_{\text {eq }}<12.5 \mathrm{~mm}\right)$, Group B - middle sized pellets $\left(3.0 \leq W \leq 3.5 \mathrm{~g}, 12 \leq D_{\mathrm{eq}} \leq 14 \mathrm{~mm}\right)$ and Group C - large sized pellets $\left(W>3.5 \mathrm{~g}, D_{\text {eq }}>13.5 \mathrm{~mm}\right)$. It was reported that despite the similar characteristics (hardness and density), the pellets from Group $\mathrm{C}$ had a higher wear rate compared to the pellets from Group A. This was found to be due to some difference in the wear mechanisms caused by the experimental conditions. In this study, the wear experiments were conducted using pellets of Group A and Group $\mathrm{C}$ as well as for pellets without a prior separation (denoted as Mixed). For each experiment, about $700 \mathrm{~g}$ of pellets were placed in three layers in the container and rotated at 240 RPM for 10 minutes and using an inlet flow rate of compressed air of 8 liter/min. A volumetric flow rate of $8 \mathrm{liter} / \mathrm{min}$ in inlet corresponds to a vertical air velocity in the container of $0.013 \mathrm{~m} / \mathrm{s}$. The applied load varied from 1 to $3 \mathrm{~kg}$. Table 1 summarizes the experiments performed under different conditions.

Before the wear experiments, the pellets were cleaned by compressed air to remove dust from the surface of the pellets. In addition, the weight of the pellets was measured before $\left(W_{0}\right)$ and after $\left(W_{t}\right)$ the rotation experiment lasting for 10 minutes. Thereafter, the wear rate $(W R)$ of the pellets during rotation was calculated according to Eq. (1):

$$
W R=\frac{W_{0}-W_{t}}{W_{0} \cdot t} \cdot 100 \%
$$

where $t$ is time.

\subsection{Evaluation of PSD of Dust Particles}

The outlet was connected to a particle analyzer, Dekati ELPI+ (Electrical Low Pressure Impactor), which can measure the particle concentration in the size range of an aerodynamic diameter $\left(d_{a}\right)$ ranging from $6 \mathrm{~nm}$ to $10 \mu \mathrm{m}$. Before starting the experimental measurements, the air in the container was analyzed to obtain the background level of the particle concentrations in injected air. The particles during measurement are charged in a corona charger and the total charge collected on an impactor stage in a specific size class of the ELPI+ analyzer is converted into concentration (number per unit volume of air, $N_{\mathrm{V}}$ ). Finally, the concentration of the particles in the fixed 14 size intervals of $d_{a}$ is

Table 1. Experimental conditions.

\begin{tabular}{cccc}
\hline Exp. & Type of pellets & $\begin{array}{c}\text { Weight of charge } \\
(\mathrm{g})\end{array}$ & $\begin{array}{c}\text { Applied load } \\
(\mathrm{kg})\end{array}$ \\
\hline GA1, GA2, GA3 & A & $701.8-708.1$ & 3 \\
GC1, GC2, GC3 & C & $700.2-703.2$ & 3 \\
M1, M2, M3, M4 & Mixed & $702.5-706.6$ & 3 \\
M5, M6 & Mixed & $702.2-703.4$ & 2 \\
M7, M8 & Mixed & $700.7-703.1$ & 1 \\
\hline
\end{tabular}


reported. Translation of aerodynamic diameter measured by the particle analyzer into equivalent diameter of spherical particles can be done by using the following equation for the Stokes diameter $\left(d_{s}\right):^{18)}$

$$
d_{a}=d_{s}\left(\frac{\rho_{p}}{\rho_{a}}\right)^{1 / 2}
$$

where $\rho_{a}$ is the density of a water droplet $\left(1000 \mathrm{~kg} / \mathrm{m}^{3}\right),{ }^{19)}$ $\rho_{p}$ is the density of particles (5 $200 \mathrm{~kg} / \mathrm{m}^{3}$ for hematite). ${ }^{20)}$ In this case, the size range of the dust particles measured by the ELPI+ analyzer corresponds to $0.003-4.47 \mu \mathrm{m}$ of the Stokes diameter for spherical particles.

The generated "heavy" dust, which stayed in the container, was completely collected after each experiment to evaluate the dust weight and particle size distribution. Also, two different techniques were applied for evaluation of this PSD.

In Method I (SEM method), a weighed amount of dust was dispersed in $\sim 20 \mathrm{ml}$ methanol by using an ultrasonic bath. Thereafter, the solution was filtered through a PTFE film filter with an open pore size of $0.1 \mu \mathrm{m}$. Then the dust particles on the surface of a film filter were investigated by using a scanning electron microscope (SEM) at magnifications of 300 to 1000 . Also, an image processing software called "ImageJ" was used for the measurement of each dust particles on the SEM images. For each particle maximum length $\left(L_{\max }\right)$, the circularity factor $(C F)$ and the area of particle $\left(A_{p}\right)$ were determined. The circularity factor is defined as follows:

$$
C F=\frac{4 \pi \cdot A_{p}}{P_{p}^{2}} .
$$

where $P_{p}$ represent the perimeter of a particle on a SEM image.

The equivalent diameter $\left(d_{e q}\right)$ of the particle, which represents the diameter of a circle having the same area as the measured area of the particle, was calculated according to following equation:

$$
d_{e q}=\sqrt{\frac{4 A_{p}}{\pi}}
$$

The PSD of the dust particles was determined as the num- ber of particles in the respective size range per unit weight $\left(N_{W}\right)$ of dust. This was calculated as follows:

$$
N_{W}=\frac{n \cdot A_{f}}{A_{o b s} \cdot W_{d}}
$$

where $n$ is the number of investigated particles in the given size range, $A_{f}$ is the total area of PTFE filter with dust particles $\left(=1220 \mathrm{~mm}^{2}\right), A_{o b s}$ is the observed area on PTFE filter and $W_{d}$ is the total weight of dust dispersed on the film filter. Figure 2 shows typical commercial pellets and dust particles observed on film filters.

Method II (LD method) used a CILAS 1064 laser diffraction particle size analyser (liquid mode) with a measurement of particle size in the range from 0.04 to $500 \mu \mathrm{m}$. The Fraunhofer theory of diffraction is used for determination of the dust PSD results based upon diffraction patterns. However, the results obtained based upon a Fraunhofer approximation are not very accurate for submicron particles. ${ }^{15)}$ Laser diffraction particle size analyser measures the equivalent diameter $\left(d_{e q}\right)$ of particles in random orientations. Assuming that the analysed particles are spheres, the volume fractions of particles in different size intervals are calculated. The obtained volume fractions were converted to $N_{W}$ by calculating the weight and number of particles in each size interval.

\section{Results and Discussion}

\subsection{Dust Generation and Friction Forces}

In a previous study, ${ }^{14)}$ it was found that the wear rate of commercial pellets in a planetary mill can significantly depend on their size. More specifically, the wear rate of large sized pellets (Group C, $13.5<D_{\text {eq }}<15.0 \mathrm{~mm}$ ) was about on $10-20 \%$ higher than that of the small sized pellets (Group A, $9.5<D_{\text {eq }}<12.5 \mathrm{~mm}$ ). It was reported that the dust, which was generated from large size pellets, contain higher amounts of large sized particles $(>20 \mu \mathrm{m})$. This was due to the higher contribution of impact/collisions during these wear experiments. Whereas, the small sized pellets produced a higher amount of small sized particles (0-10 $\mu \mathrm{m})$ because the sliding/abrasion process was dominating in these wear trials. A constant load of pellets (60-62 g) was used in the wear experiments which created different (a)

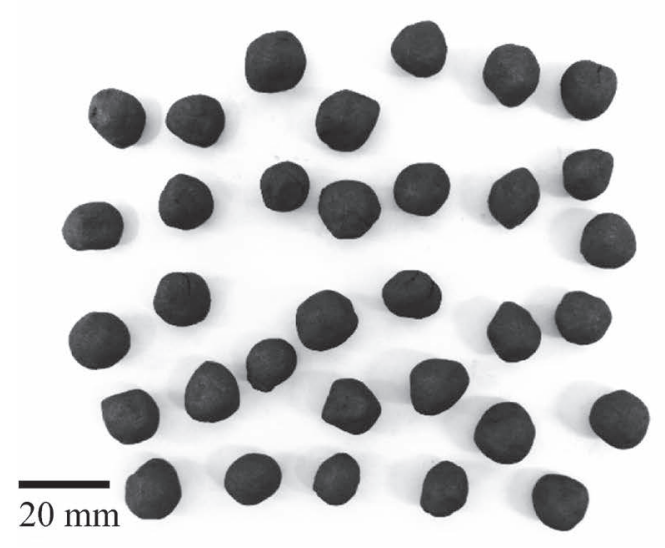

(b)

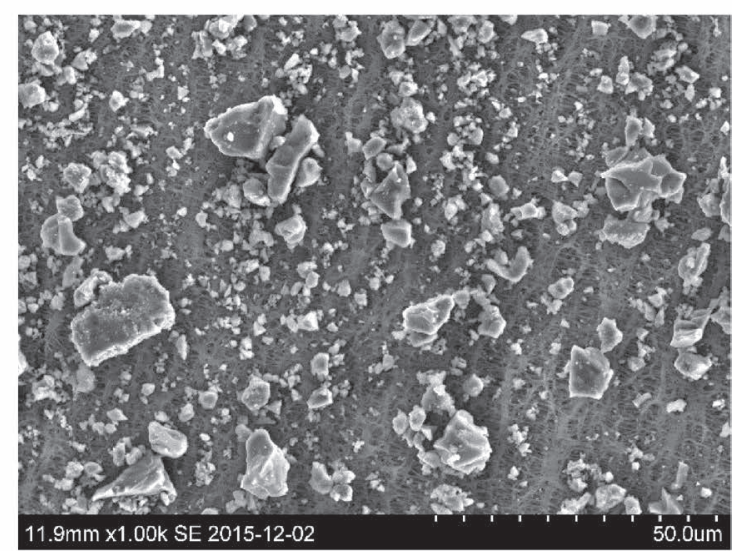

Fig. 2. (a) Typical industrial iron ore pellets and (b) typical dust particles observed on PTFE film filter. 
experimental conditions. Thereby, the above mentioned results were obtained.

In this study, the wear rates of different sized pellets were investigated by using an experimental setup in which the sliding/abrasion is the major mechanism for wear of pellets. Figure 3(a) presents the wear rate $(W R)$ for Group A, C and Mixed (without separation of pellets into groups depending on their size and weight) pellets obtained in the experimental trials during 10 minutes by applying a load of $3 \mathrm{~kg}$. It can be seen that similar wear rates $(0.66 \pm 0.04$ $\mathrm{wt} \% / \mathrm{min}$ ) were obtained for all groups of pellets. The friction force generated in the pellet bed, which is continuously measured during the total rotation time, is shown in Fig. 3(b) as a function of time. Similar to the wear rate, the generated friction forces are not influenced by the classification of pellets in groups i.e. on an average friction force for all cases is $3.81 \pm 0.018 \mathrm{~N}$. This suggests that the experimental conditions and wear mechanism (sliding/abrasion) in these trials were similar for the different sized pellets. Therefore, the Mixed pellets (without separation into groups) were used for the later experiments. Moreover, Fig. 3 indicates that a good repeatability of the experimental results can be achieved using this equipment.
The effect of different applied loads (from 1 to $3 \mathrm{~kg}$ ) on wear rate and generated friction forces is presented in Fig. 4. As can be seen in Fig. 4(a), the average wear rate increases linearly with an increased applied load (a correlation coefficient for obtained results is $\mathrm{R}=0.999$ ). On an average, the wear rate can be increased on $\sim 67 \%$ by increasing applied load from 1 to $3 \mathrm{~kg}$. Figure 4(b) shows the average friction forces measured during $10 \mathrm{~min}$ of rotation versus to the applied load. It can be seen that the increase in friction forces with an increased applied load is also a linear function with an $\mathrm{R}$ value of 0.998 .

\subsection{Characteristics of Dust}

In this study, the dust generated during the wear experiments is categorized as follows: i) $\mathrm{D}_{0}$ is the total dust generated during an experiment; ii) $\mathrm{D}_{1}$ is the "heavy" dust which stays at the bottom of container after an experiment and iii) $\mathrm{D}_{2}$ is the "light" dust which exits with the air flow during experiment. In addition, $\mathrm{D}_{2}$ is further categorized as the amount of dust measured by a particle analyzer $\left(\mathrm{D}_{2 \mathrm{PA}}\right)$ and the remaining $\mathrm{D}_{2}$ which is deposited on the walls and on the upper surface of the porous plate in chamber $\left(\mathrm{D}_{2 \mathrm{~L}}\right)$.

The mass of $\mathrm{D}_{0}$ dust was determined as a difference a)

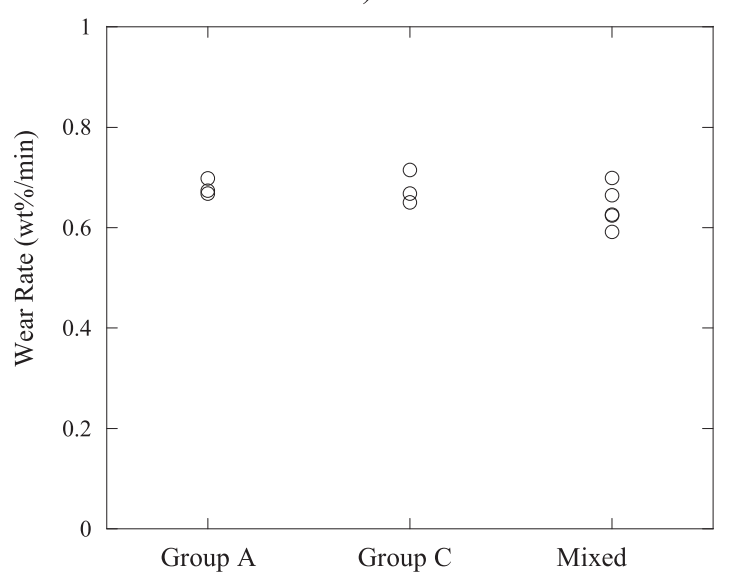

b)

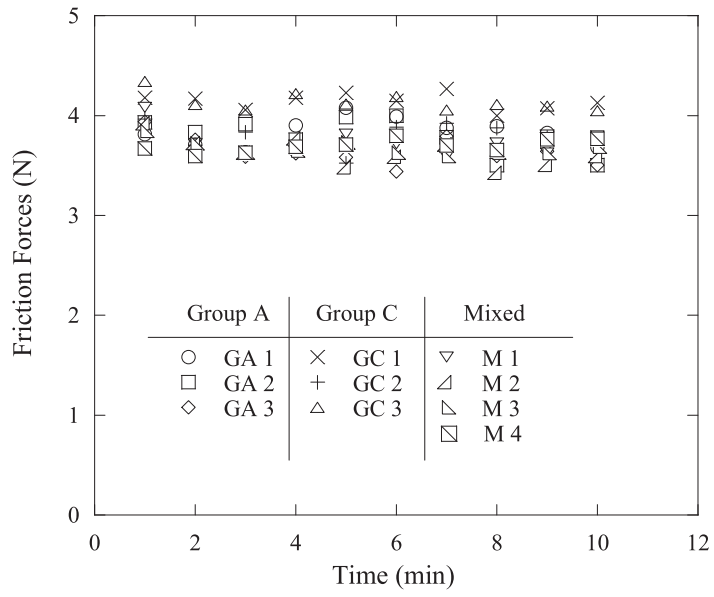

Fig. 3. (a) Measured wear rate after $10 \mathrm{~min}$ of rotation and (b) the friction forces for different pellets.

a)

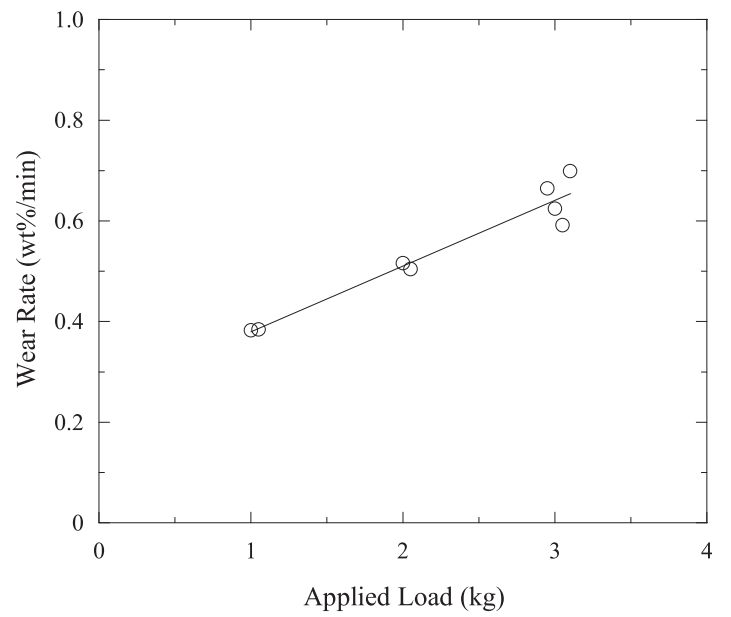

b)

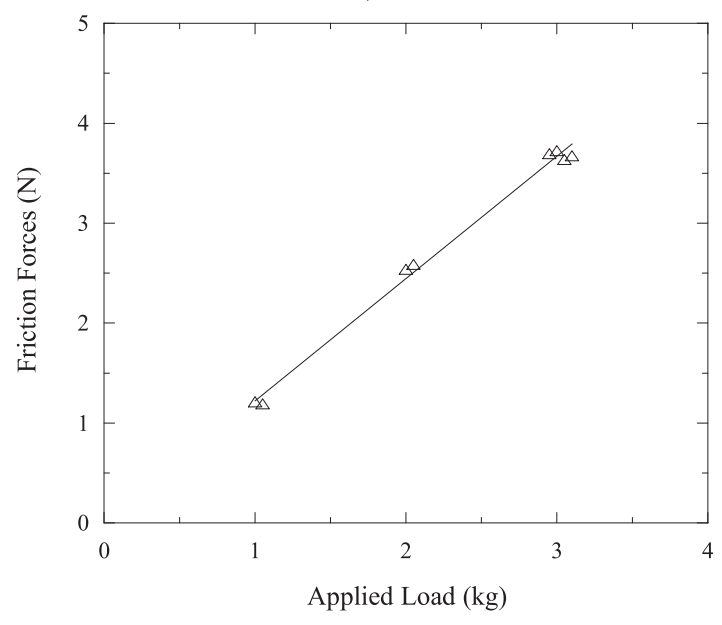

Fig. 4. Effect of varied applied loads on (a) the wear rate and (b) the average friction forces during the M1- M8 experiments. 
between the measured weights of pellets before and after the rotation during a specific time. Heavy $\mathrm{D}_{1}$ dust was collected from the bottom of container after an appropriate rotation time. Thereafter, it was weighed and used to investigate the influence of the experimental conditions on the PSD of $\mathrm{D}_{1}$.

The PSDs of dust $\mathrm{D}_{1}$ obtained for varied applied loads by the laser diffraction analysis (LD method) are presented in Fig. 5. It appears that the $D_{1}$ dusts generated under varied applied load conditions have similar PSDs. However, the number of particles with a $d_{e q}>10 \mu \mathrm{m}$ for $3 \mathrm{~kg}$ applied load is slightly lower than that for lower applied loads. It can be clearly seen in Fig. 6, which presents the variation in $N_{W}$ of particles of $\mathrm{D}_{1}$ dust in three size ranges, i.e. small $\left(1 \mu \mathrm{m} \leq d_{e q} \leq 5 \mu \mathrm{m}\right)$, medium $\left(5 \mu \mathrm{m}<d_{e q} \leq 10 \mu \mathrm{m}\right)$ and large $\left(d_{e q}>10 \mu \mathrm{m}\right)$. It can be seen that $N_{W}$ value of small sized particles for $3 \mathrm{~kg}$ is on $\sim 13 \%$ higher than that for 1 $\mathrm{kg}$. For medium sized particles a clear tendency couldn't be observed, whereas the $N_{W}$ value of large sized particles is higher (on an average $\sim 6 \%$ ) for lower applied loads. The variation of the $N_{W}$ values in the different size ranges can be attributed to the different extents of the friction force

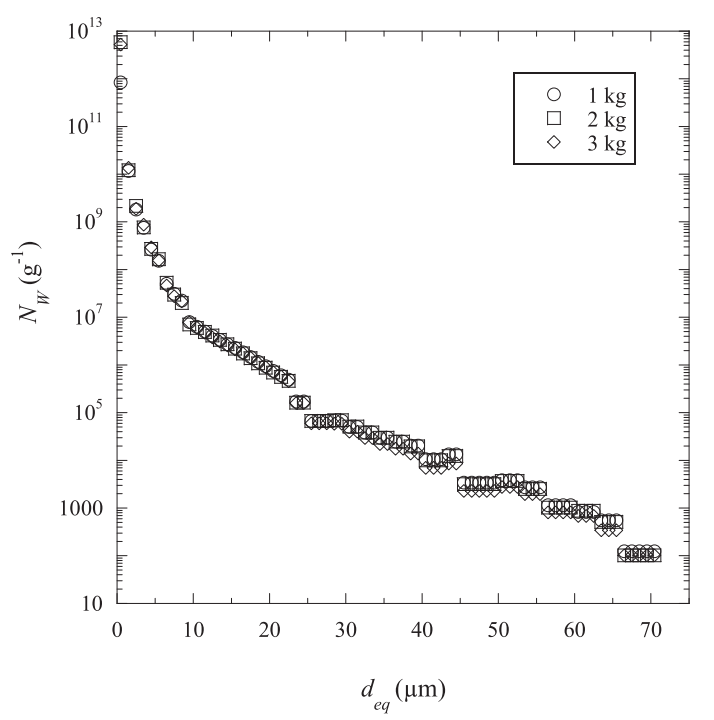

Fig. 5. Particle size distributions of the $D_{1}$ dust generated under varied applied loads in Exp. M8, M6 and M2 and obtained by using the LD method. between the pellets in the pellet bed at different applied loads. It is apparent that the large applied load promoted higher sliding contacts and friction force between pellets. As a result, it also contributed to the generation of larger number of small sized particles.

The difference in PSDs of dust generated due to different mechanisms of wear has been discussed in a previous study, ${ }^{14)}$ where MPBO pellets classified according to size and weight were subjected to mechanical wear. It has been reported that the dust generated during mechanical wear of Group A (small size) pellets dominates in fine particles in comparison to that of Group C (large size) pellets. It was suggested that dust produced due to sliding/abrasion of pellets is fine, whereas relatively coarse dust is generated due to impact/collisions of pellets. The PSD values of $\mathrm{D}_{1}$ dust for Mixed pellets determined by using SEM method in this study were compared to the PSD values of Group A and Group C pellets from a previous study. ${ }^{14)}$ Since the used equipment and conditions of experiments in the previous and given studies are different, the particle size distributions of dusts generated in different experiments were compared at an approximately same wear amount of pellets $(\sim 6-8 \mathrm{wt} \%$ from initial weight of pellets). This condition corresponds to the dust generated after $4 \mathrm{~min}$ at a rotation speed of 400 RPM in the previous experiments and the dust generated after $10 \mathrm{~min}$ at a rotation speed of $240 \mathrm{RPM}$ in the current study.

The PSDs of $\mathrm{D}_{1}$ dusts produced at 1 and $3 \mathrm{~kg}$ applied loads and determined by the SEM method are compared to the PSDs from previous experiments in Fig. 7. It can be seen in both figures that number of coarse particles $\left(L_{\max }>20\right.$ $\mu \mathrm{m})$ is $\sim 40$ to $70 \%$ higher for Group C pellets as compared to other PSDs, where pellets are relatively more vulnerable to collisions as compared to Group A pellets. Moreover, the number of fine particles $\left(L_{\max } \leq 10 \mu \mathrm{m}\right)$ is $\sim 13$ to $40 \%$ for $3 \mathrm{~kg}$ as compared to other PSDs. This can be explained by somewhat higher extend of friction force in the pellet bed under $3 \mathrm{~kg}$ applied load. It should be mentioned that some amount of particles with $d_{e q} \leq 5 \mu \mathrm{m}$ (corresponding approximately to $L_{\max } \leq 10 \mu \mathrm{m}$ ) in the current experiments has been removed along with injected air and analyzed by particle counter. Therefore, the number of these fine particles in the current experiments was considerably higher than that a)

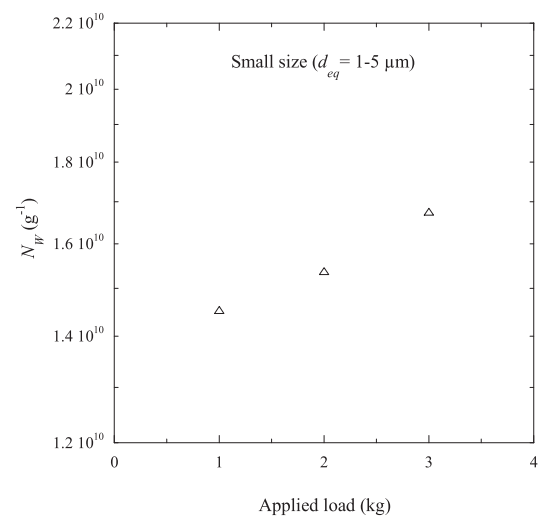

b)

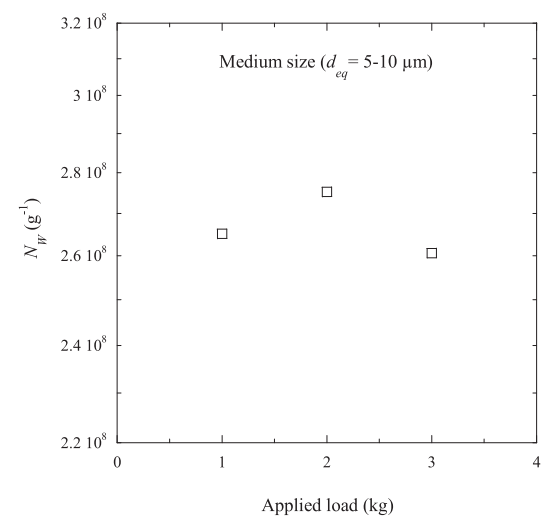

c)

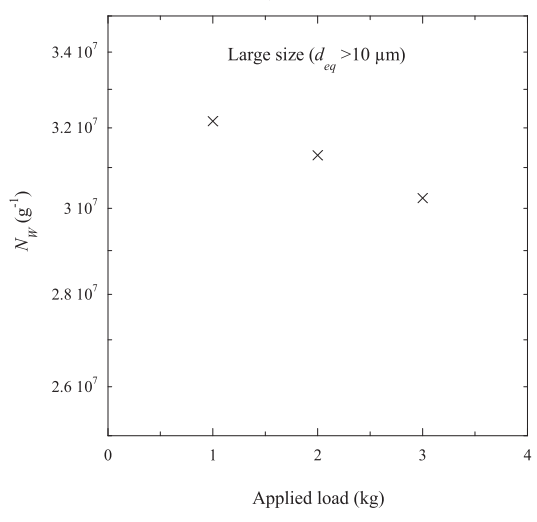

Fig. 6. Variation in $N_{W}$ values for (a) small, (b) medium and (c) large sized particles in $\mathrm{D}_{1}$ dust due to varied applied loads (Exp. M8, M6 and M2). 
a)

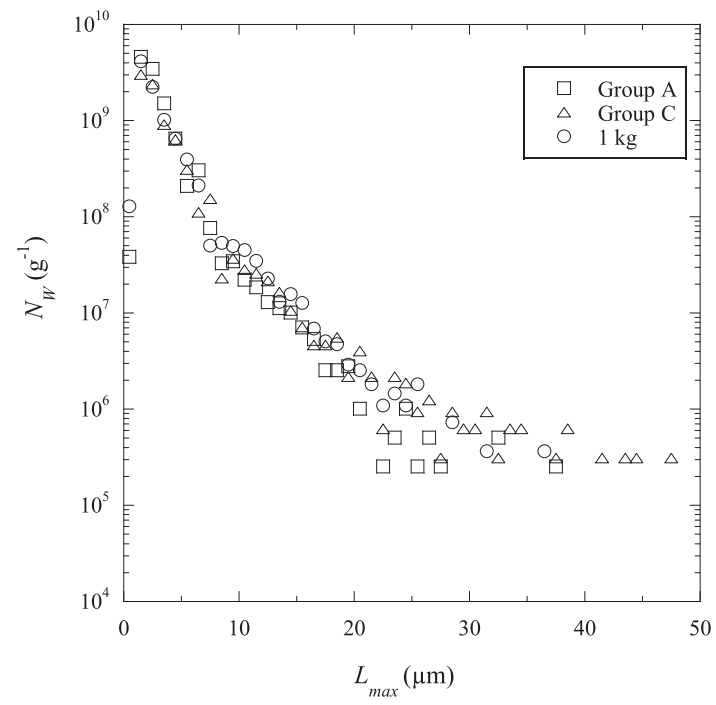

b)

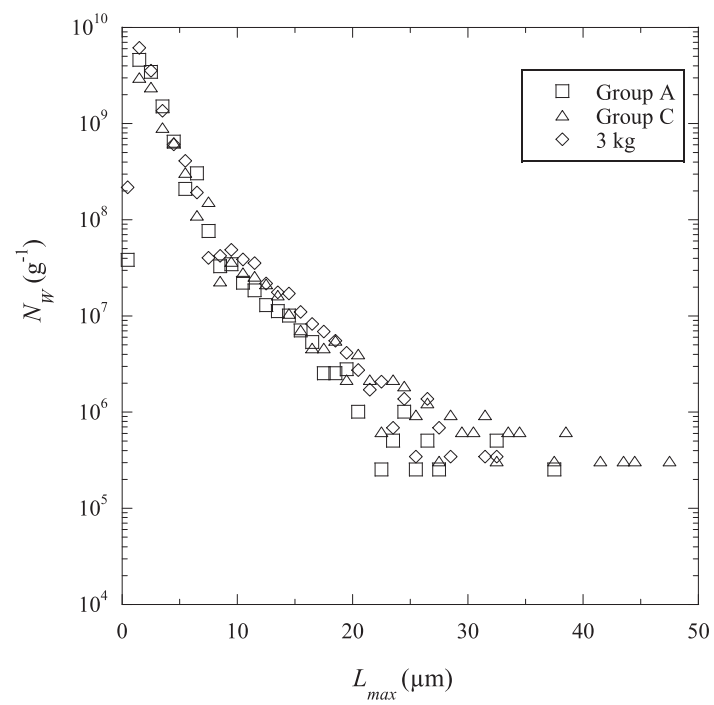

Fig. 7. Comparison of PSDs in $D_{1}$ dust generated under (a) $1 \mathrm{~kg}$ (Exp. M8) and (b) $3 \mathrm{~kg}$ (Exp. M2) of applied load and PSDs in dust of Group A and Group C pellets from previous experiments ${ }^{14)}$ obtained by using the SEM method.

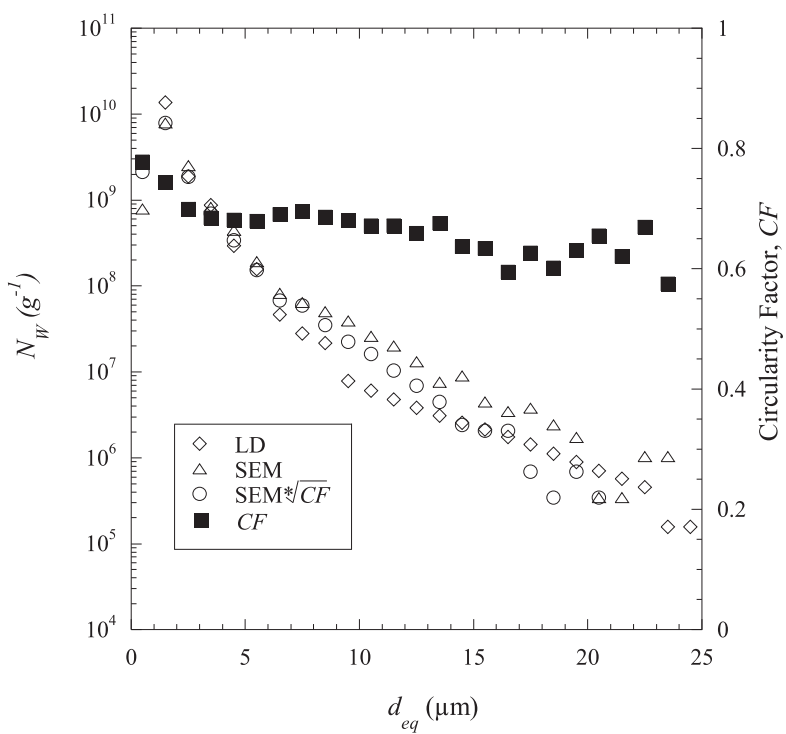

Fig. 8. Particle size distributions of $D_{1}$ dusts of Exp. M2 obtained by the SEM and LD methods as well as the circularity factor of particles in different size intervals.

in the previous experiments. It may be safely suggested that abrasion in these experiments has been the dominating mechanism of dust generation, due to presence of an externally applied load. It is important to mention that the applied loads in the current experiments (1-3 kg, which corresponds to $0.98-2.94 \mathrm{daN}$ ) are much lower compared to the crushing strength of the used MPBO pellets $(220 \mathrm{daN}),{ }^{16)}$ since very high applied loads might crush the pellets and generate the coarse particles found in the dust.

A comparison of PSDs of $\mathrm{D}_{1}$ dust obtained by using the LD and SEM methods is shown in Fig. 8 for generated dust during experiment M2. It can be seen that both PSDs show a similar tendency, but that $N_{W}$ values obtained from the SEM method $\left(N_{W, S E M}\right)$ are significantly larger than those from the LD method $\left(N_{W, L D}\right)$. For small sized particles $\left(d_{e q} \leq 5 \mu \mathrm{m}\right)$, $N_{W, S E M}$ and $N_{W, L D}$ values are very similar (on average $N_{W, S E M} /$ $N_{W, L D}$ ratio is $\left.1.09 \pm 0.4\right)$ whereas this $N_{W, S E M} / N_{W, L D}$ ratio is
$2.71 \pm 1.7$ for particles with $d_{e q}>5 \mu \mathrm{m}$. Li et al. ${ }^{17)}$ has also reported a similar discrepancy between PSD values in size range of 45-90 $\mu \mathrm{m}$ obtained from image analysis (IA) and from laser diffraction (LD) analysis determinations. This difference between PSD values obtained from the SEM and LD methods can arise due to the differences between the principles of the size measurements and determinations of the $d_{e q}$ values used in both these techniques. In the SEM method, the equivalent size of observed particles $\left(d_{e q}\right)$ is determined from their maximum projection area. This is due to that they lie on a filter surface with a particle plane having the maximum area. As a result, the equivalent size of most plate-like dust particles obtained by the SEM method can be overestimated. In the LD method, the equivalent size is determined according to the random orientation of the particles in a laser diffraction analyzer. In this case, the size of some plate-like dust particles can be underestimated depending on their orientation in the laser diffraction zone. Li et $a l .{ }^{17)}$ proposed that the PSD obtained by IA ( $\left.\operatorname{PSD}_{I A}\right)$ can be translated to the PSD of LD $\left(\mathrm{PSD}_{L D}\right)$ according to the following relationship:

$$
\operatorname{PSD}_{L D} \approx \sqrt{S} \cdot \operatorname{PSD}_{I A}
$$

where $S$ is the shape factor called "sphericity". This shape factor is equal to the circularity factor $(C F)$ used in the current study.

Figure 8 also presents the $\operatorname{PSD}_{\left(\mathrm{SEM} \cdot V_{C F}\right)}$ obtained after conversion according to Eq. (6) along with the $C F$ value for each size class. It can be seen that the deviation between $\operatorname{PSD}_{\left(\mathrm{SEM} \cdot \sqrt{C F}_{C}\right)}$ and $\mathrm{PSD}_{L D}$ has decreased, though it still exists especially for $d_{e q}>5 \mu \mathrm{m}$.

As mentioned earlier, ELPI+ particle analyzer was used for an evaluation of the "light" dust $\left(D_{2 P A}\right)$. Figure 9(a) shows the PSDs of dust particles measured by the particle analyzer for the background air before the experiment and at the 1st and 10th minute in experiment M2. It can be seen that the number of particles per unit volume of air $\left(N_{\mathrm{V}}\right)$ up to $0.1 \mu \mathrm{m}$ are similar for all the presented PSDs. Moreover, the $N_{\mathrm{V}}$ values for particles $>0.1 \mu \mathrm{m}$ in the background air are 
a)

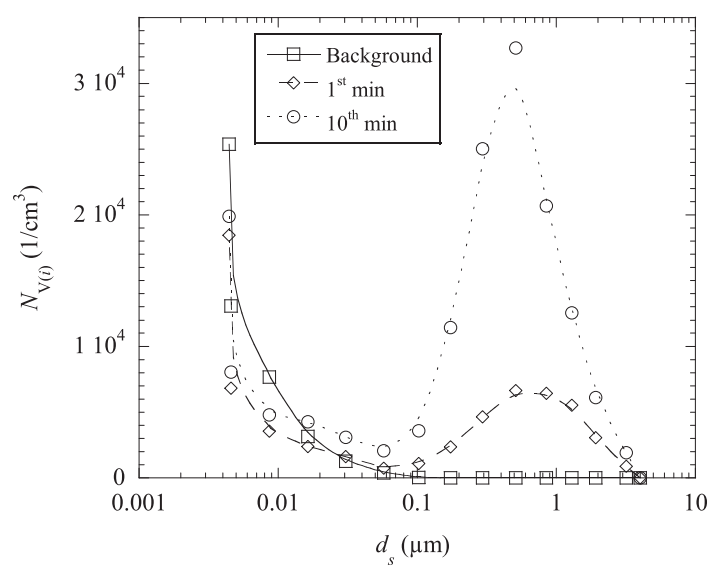

b)

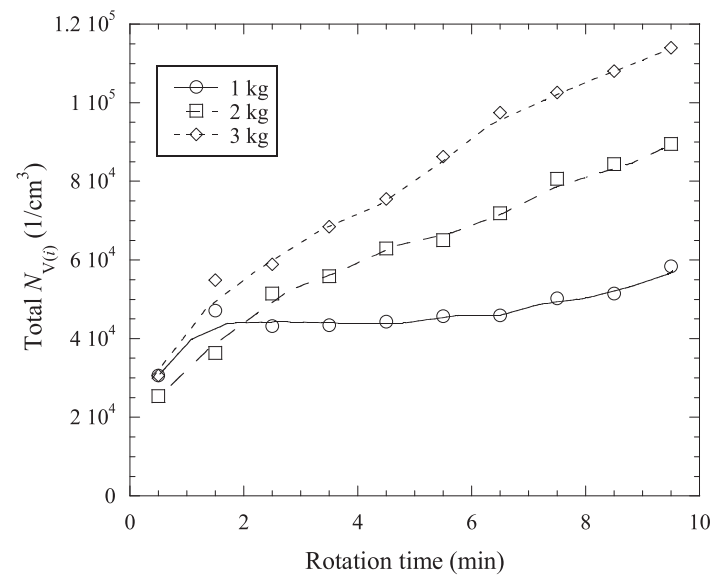

Fig. 9. (a) A comparison of background air level and particle size distributions of $D_{P A}$ dust obtained by ELPI+ and (b) the total concentrations of particles in the dust analyzed by ELPI+ in the experiments at different applied loads (Exp. M8, M6 and M2) and times.

a)

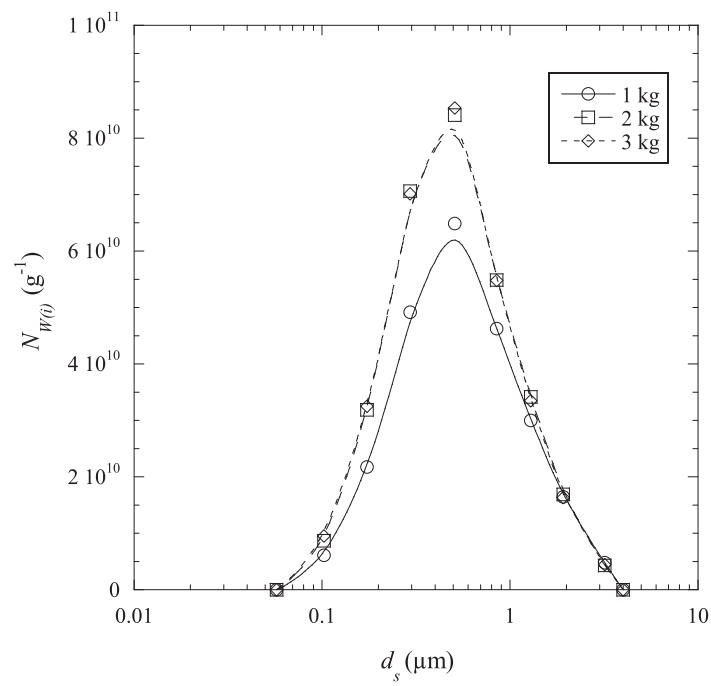

b)

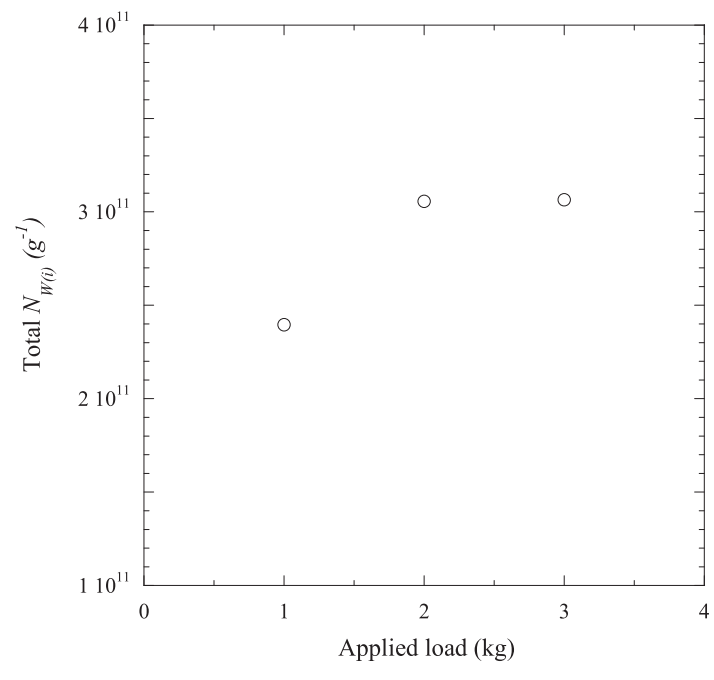

Fig. 10. Effect of the applied load on (a) the particle size distributions and (b) the total $N_{W}$ value of $\mathrm{D}_{2 \mathrm{PA}}$ dust measured by ELIP + during 10th minutes of rotation $(i=10)$.

negligibly small i.e. $\sim 0.1 \%$ of total $N_{\mathrm{V}}$. Similar results were obtained in other wear experiments of this study. Therefore, it was concluded that the most particles up to a size of 0.1 $\mu \mathrm{m}$ correspond to the air background. Thus, they were not considered in the evaluation of the PSD values of the generated dust. The total numbers of particles larger than 0.1 $\mu \mathrm{m}$ in the $\mathrm{D}_{2 \mathrm{PA}}$ dusts measured at $i$-th minute are presented in Fig. 9(b) for experiments at different applied loads. It is apparent that the concentration of the analyzed dust $\left(N_{\mathrm{V}(i)}\right)$ increases significantly with an increased rotation time and applied load. Similar tendencies were obtained in other wear experiments and can be justified by increasing amount of accumulated dust in the chamber with an increased rotation time and a higher wear rate for higher applied loads.

Comparison of PSDs for $\mathrm{D}_{2 \mathrm{PA}}$ dust particles measured at 10th minute $(i=10)$ of experiments under varied applied load is shown in Fig. 10. In this case, the $N_{\mathrm{V}(10)}$ values measured by the particle analyzer are represented as the number of particles per $1 \mathrm{~g}$ of dust. It can be seen in Fig. 10(a) that the peaks of all PSDs are at $d_{s} \sim 0.5 \mu \mathrm{m}$. However, the $N_{\mathrm{W}(10)}$ values obtained for 2 and $3 \mathrm{~kg}$ applied loads are considerably higher than that for a $1 \mathrm{~kg}$ load. The same tendency was obtained for the total $N_{\mathrm{W}(10)}$ values, which were obtained by a summation of the $N_{\mathrm{W}(10)}$ values for all particle size intervals, as shown in Fig. 10(b). It indicates that a larger number of small sized particles is generated under a higher applied load, as was also observed by LD method for $\mathrm{D}_{1}$ dust.

The amount of measured $\mathrm{D}_{2 \mathrm{PA}}$ dust corresponds to about $3.7-5.3 \mathrm{wt} \%$ of the total weight of the $\mathrm{D}_{0}$ dust. The weight of the small sized particles $\left(d_{e q} \leq 5 \mu \mathrm{m}\right)$ in the $\mathrm{D}_{0}$ dust was roughly evaluated by a summation of the respective $N_{W}$ values for $\mathrm{D}_{1}$ and $\mathrm{D}_{2 \mathrm{PA}}$ without a consideration of the dust losses during the experiments $\left(\mathrm{D}_{2 \mathrm{~L}} \sim 0\right)$. In this case, the amount of measured $\mathrm{D}_{2 \mathrm{PA}}$ dust, which was removed from container with a gas flow, corresponds to only $12-17 \mathrm{wt} \%$ of $\mathrm{D}_{0}$ dust in the size range of $1-4.5 \mu \mathrm{m}$. It can be explained by an additional resistance of the pellet bed and the upper loading plate, a low air velocity and a plate-like morphology of dust particles. It was found that free area (holes) between the pellets in the bed in horizontal section is about 
$11 \%$ of the total horizontal area of the container. However, this value of the free area may vary due to movements of pellets in the bed during an experiment and variation in the size and the shape of pellets. Also, this value was calculated for charge bed of 150 spherical pellets having an average pellet weight of $3 \mathrm{~g}$ and an average diameter of $12.25 \mathrm{~mm}$. Further, the free area of holes in the upper loading plate is only $\sim 9.5 \%$ of the total area of this plate.

The other reasons for the less weight percentage of particles collected by ELPI+ can be the low air velocity and the morphology of dust particles. As was mentioned above, the generated dust particles have mostly a flake or a plate shape. During uplifting of the particles, the area of particles perpendicular to air flow (projected area) is of more importance as it defines the drag force which shall act on the particles to be lifted. The velocity of a gas $\left(U_{t}\right)$ required to lift up a particle of known mass $(m)$ and projected area $\left(A_{p}\right)$ of particle can be calculated according to following relationship: ${ }^{21)}$

$$
U_{t}=\left[\frac{2 m g\left(\rho_{p}-\rho_{g}\right)}{\rho_{g} \rho_{p} C_{D} A_{p}}\right]^{1 / 2}
$$

where $\rho_{p}$ is the density of particle $\left(5200 \mathrm{~kg} / \mathrm{m}^{3}\right.$ for hematite) ${ }^{20)} \rho_{g}$ is the density of gas $\left(1.29 \mathrm{~kg} / \mathrm{m}^{3}\right.$ for air $),{ }^{22)} \mathrm{g}$ is the acceleration of gravity. $C_{D}$ is the coefficient of drag force. The value of $C_{D}$ can be determined depending on the value of the Reynolds number of particle $\left(R e_{p}\right)$ as follows: ${ }^{23)} C_{D}=$ $24 / R e_{p}$ for $R e_{p}<0.4, C_{D}=10 /\left(R e_{p}{ }^{1 / 2}\right)$ for $0.4<R e_{p}<500$ and $C_{D}=0.43$ for $500<R e_{p}<200000$.

It is apparent that for particles having a constant weight/ volume, a lower velocity of air is required for a particle having larger $A_{p}$ value. Therefore, the orientation of dust particles in the air flow can significantly influence their uplift. Figure 11 shows the variations of the required gas velocity for the uplift of a small sized dust particle $\left(d_{e q} \leq 5\right.$ $\mu \mathrm{m})$ and a large observed plate-like particle having different orientations (projected area) in the gas flow. The dimensions (length, width and thickness) and different projected areas depending on the orientations $\left(A_{p 1}, A_{p 2}\right.$ and $\left.A_{p 3}\right)$ and measured by using Image $\left(A_{p(I J)}\right)$ are given in Table 2 . It can be seen in Fig. 11 that the required gas velocity for one platelike particle can be varied by 22 to $30 \%$ on average depending on the dimensions of this dust particle and orientation in the air flow. However, the air velocity in the container during the current experiments $(\sim 0.013 \mathrm{~m} / \mathrm{s})$ is much larger compared to the $U_{t}$ values for small particles (Fig. 11(a)). It means that regardless of orientation, all the small sized particles $\left(d_{e q} \leq 5 \mu \mathrm{m}\right)$ should have been removed from the container. Hence, the resistance offered by the pellet bed is the major reason for a smaller weight percent of small sized particles, which were captured by the air flow and which were measured by the particle analyzer.

The required air velocity for large particles are much higher than $0.013 \mathrm{~m} / \mathrm{s}$. Further, it tends to significantly increase with a decreased projected area of the plate-like dust particles. Moreover, it should be noted that the real thickness $(z)$ of the large size dust particles is significantly lower than the assumed half of its width. In this case, the required air velocity for the uplift of such particles should be significantly larger. Hence, the influence of the orientation and the morphology of particles is of great importance for flow of particles especially for large sized particles. a)

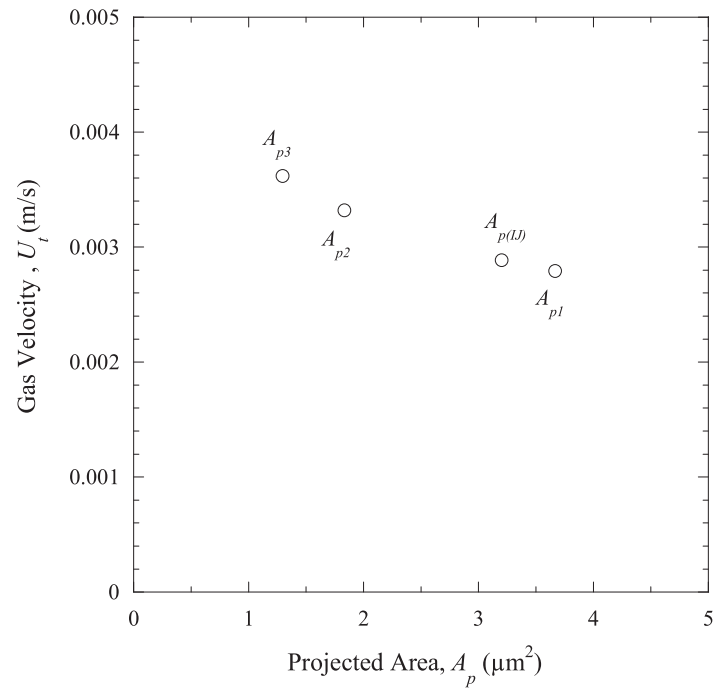

b)

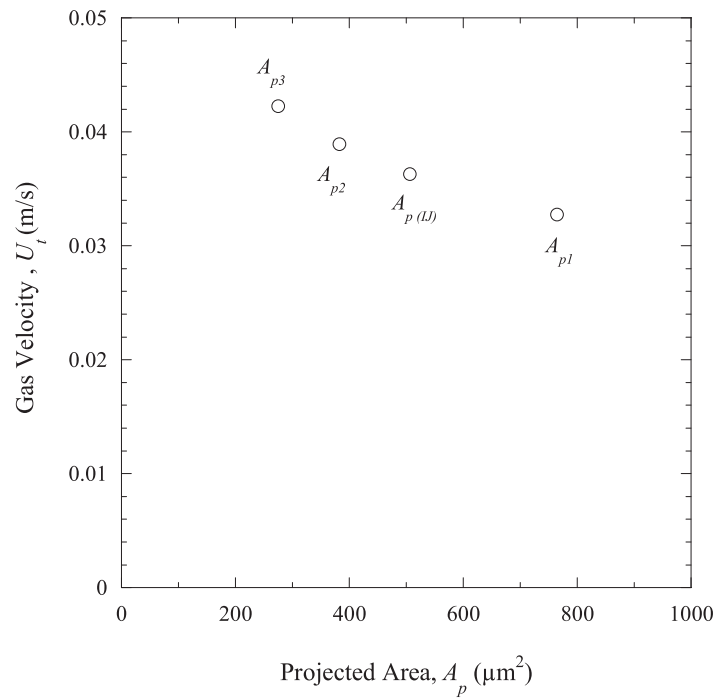

Fig. 11. Variation in required gas velocity for the uplifting of a) a small sized and b) a large sized particle having different orientations and projected area $\left(A_{p}\right)$ in the gas flow.

Table 2. The dimensions and projected area $\left(A_{p}\right)$ of the two particles which were considered to calculate the required air velocity at different orientations in air flow.

\begin{tabular}{|c|c|c|c|c|c|c|c|}
\hline Dust particle & Length, $x(\mu \mathrm{m})$ & Width, $y(\mu \mathrm{m})$ & Thickness, $z=y / 2(\mu \mathrm{m})$ & $A_{p 1}=x \cdot y\left(\mu \mathrm{m}^{2}\right)$ & $A_{p 2}=x \cdot z\left(\mu \mathrm{m}^{2}\right)$ & $A_{p 3}=y \cdot z\left(\mu \mathrm{m}^{2}\right)$ & $A_{p(I J)}\left(\mu \mathrm{m}^{2}\right)$ \\
\hline Small & 2.3 & 1.6 & 0.8 & 3.7 & 1.8 & 1.3 & 3.2 \\
\hline Large & 32.6 & 23.5 & 11.8 & 766.1 & 383.1 & 276.1 & 506.2 \\
\hline
\end{tabular}




\section{Conclusions}

In this study, experiments have been carried out to simulate the dust generation due to the mechanical wear of iron ore pellets during the transportation and handling as well as during the descending in a blast furnace. A varied external load was applied on a bed of pellets to observe the change in the friction forces and the amounts of dust generated due to the pellets movements. Based upon the presented experimental results the following conclusions can be made:

(1) The friction forces among the pellets and dust generation in a pellet bed directly increases with increased applied load. More specifically a $\sim 67 \%$ increase is observed for both the wear rate and the friction forces with an increased applied load from 1 to $3 \mathrm{~kg}$.

(2) A higher friction in the pellet bed under higher applied load results in increased contribution of abrasion mechanism and produce a higher number of small sized dust particles $\left(d_{e q} \leq 5 \mu \mathrm{m}\right)$.

(3) The particle size distributions (PSDs) of dust obtained by laser diffraction (LD method) and image analysis (SEM method) can be well correlated by considering the circularity factor $(C F)$ for particles having high $C F$ values. Whereas, for large sized dust particles having plate-like shape and lower $C F$ values there is need to introduce some correction factor to obtain a good correlation.

(4) The air velocity required to uplift dust particles can be significantly influenced by their morphology and orientation in the air flow.

\section{Acknowledgements}

The authors are grateful to the Swedish Energy Agency and the Swedish Steel Producers' Association for the financial support. Special thanks to Prof. Ulf Olofsson at KTH for the collaboration and assistance during the experimental part of this study. Also, the authors would like to thank LKAB Sweden for providing the testing materials.

\section{REFERENCES}

1) K. Meyer: Pelletizing of Iron Ore, Springer-Verlag, Berlin, (1980).

2) M. Hallin, L. Hooey, J. Sterneland and D. Thulin: ATS Int. Steelmaking Conf., La Revue de Métallurgie, Paris, (2001), 311.

3) U. Leihalm, M. Lundgren, L. S. Okvist and B. Bkorkman: ISIJ Int., 50 (2010), 1570.

4) U. Leihalm, M. Lundgren, L. S. Okvist and B. Bkorkman: ISIJ Int., 50 (2010), 1560.

5) B. Fagerberg and N. Sandberg: Proc. 2nd Int. Symp. on Transport and Handling of Minerals, Luossavaara Kiirunavaara AB, Stockholm, (1973), 128.

6) L. M. Tavares, R. M. de Carvalho, H. C. Pereira, M. R. Bianchi and M. M. Otaviano: ETEC \& 2nd ESTAD, Stahl-Institut VDEh, Düsseldorf, (2015), 1.

7) C. R. Copeland and S. K. Kawatra: Miner. Eng., 24 (2011), 1459.

8) J. A. Halt, M. C. Nitz, S. K. Kawatra and M. Dube: Miner. Process. Extr. Metall. Rev., 36 (2015), 258.

9) J. A. Halt and S. K. Kawatra: Miner. Process. Extr. Metall. Rev., 36 (2015), 340

10) O. Sivrikaya and A. I. Arol: Int. J. Miner. Process., 123 (2013), 158.

11) C. S. Teo, A. G. Waters and S. K. Nicol: Int. J. Miner. Process., 30 (1990), 159

12) S. H. Nistala, M. Sinha, M. K. Choudhary, G. Bose and S. Sinha: Ironmaking Steelmaking, 42 (2015), 226.

13) G. Gustafsson, H. A. Haggblad, P. Jonsen and P. Marklund: Powder Technol., 241 (2013), 19.

14) M. Nabeel, A. Karasev and P. Jönsson: ISIJ Int, 56 (2016), 960.

15) R. Xu: Particle Characterization: Light Scattering Methods, Kluwer Academic Publishers New York, (2002).

16) LKAB Products Handbook, LKAB, Luleå, (2013).

17) M. Li, D. Wilkinson and K. Patchigolla: Part. Sci. Technol., 23 (2005), 265.

18) P. Kulkrandi, P. A. Bolen and K. Willeke: Aerosol Measurements: Principles, Techniques and Applications, 3rd ed., John Wiley \& Sons, Hoboken, NJ, (2011), 24.

19) W. C. Hinds: Aerosol Technology: Properties, Behavior and Measurement of Airborne Particles, 2nd ed., John Wiley \& Sons, Hoboken, NJ, (1999), 53.

20) SME Mining Reference Handbook, SME, CO, (2002), 13

21) J. Gabitto and C. Tsouris: Powder Technol., 183 (2008), 314.

22) F. E. Jones: J. Res. Natl. Bur. Stand., 83 (1978), 419.

23) M. Ichida, T. Nakayama, K. Tamura, H. Shiota, K. Araki and Y. Sugisaki: ISIJ Int., 32 (1992), 505. 